\title{
O DIREITO COMO FATO SOCIAL
}

\author{
José Carlos Vieira
}

\section{RESUMO}

Pretende-se demonstrar, neste trabalho, que o direito é sempre um fenômeno verificável na realidade social; é um fato social, portanto.

O direito, como objeto cientifico, pode ser estudado sob três dimensões: através da filosofia do direito, da ciência dogmática-normativista do direito e da sociologia juridica.

MIGUEL REALE, o conceituado jus-filósofo paulista, criador da "Teoria tridimensional do Direito", afirma que o direito é, ao mesmo tempo, fato, valor e norma; sobre esta teoria, são desenvolvidas várias considerações, em cotejo com a "Teoria critica", defendida por LUIZ FERNANDO COELHO, que vê o direito como instrumento de mutação social e não, simplesmente, um regulador da ordem social estabelecida.

A abordagem deste tema foi exaustivamente trabalhada durante as aulas de Filosofia do Direito, no Curso de Mestrado em Direito das Relações Sociais da UEL e este trabalho procura sintetizar os conhecimentos auridos.

PALAVRAS-CHA VE: Fato social; Filosofia do direito; Dogmática jurídica; Sociologia jurídica; Teoria tridimensional; Teoria crítica.

\section{INTRODUÇÃO}

\section{Razões da escolha do tema}

A escolha de um tema para estudo decorre, no mais das vezes, de variadas circunstâncias: bibliografia disponível, melhor compreensão da matéria, identificação pessoal etc, e até mesmo a influência que o professor exerce sobre o estudante.

No caso presente, dos cinco temas apresentados o que se mostrava mais atraente, pelo inusitado, era "o direito como ideologia". Ocorre que o enfoque do direito, como objeto do conhecimento tem de passar pelo estudo e suficiente compreensão dos demais planos em que o referido fenômeno é encarado. Este conhecimento, no entanto, não é algo que se adquire de imediato. Sedimenta-se com o tempo de muitas leituras e reflexões. Inveredar por um tema dessa magnitude pressupõe o domínio dos demais tópicos, à vista que a conclusão sobre a existência ou não de cargas ideológicas permeando o direito implicará numa tomada de posição. Em caso contrário, ou seja, sem o suficiente domínio dos demais quadrantes do saber jurídico, corre-se o risco de resvalar o estudo para o proselitismo político, tão prejudicial quanto a visão isenta dos dogmáticos.

O meio termo entre a visão normativista do direito e o enfoque exclusivamente ideológico do mesmo, no momento, nos pareceu o estudo do mesmo como fenomeno social. Também porque o direito visto pela sociologia jurídica, mesmo ante a constatação de que é ele ainda instrumento de manutenção da chamada ordem social, está mais próximo de uma visão crítica. Pela ótica da sociologia jurídica o direito não é fruto de uma visão particular de um indivíduo mas um fenômeno, ou um fato que ocorre no meio social. $O$ direito não é a norma abstrata, modelo de linguagem, mas um fato que se produz e é verificado do meio social.
O direito como fato social é estudado pela sociologia jurídica enquanto que para a ciência jurídica e para a filosofia do direito ele é visto como norma e como valor, respectivamente.

\section{SUJEITO, CONHECIMENTO E OBJETO}

Que o direito é um fenômeno verificável na realidade social é questão pacífica na doutrina, seja o mesmo um sistema normativo, metafísico ou simples aspecto da vida humana. Por qualquer destas vertentes do pensamento jurídico, $o$ direito será sempre um fenômeno ou conjunto de fenômenos. O homem como membro da sociedade se relaciona com este fenômeno de formas variadas. Vivencia-se o direito simplesmente conhecendo e cumprindo o que se convencionou chamar de ordenamento jurídico ou como objeto de indagação científica.

A partir do segundo enfoque, ou seja, como objeto de ciência, o contato do homem com o direito se dá pelo conhecimento. Neste momento o homem é o sujeito do conhecimento e o direito é o objeto. Segundo Luiz Fernando Coelho $(3: 37)$ o processo pelo qual o sujeito passa a conhecer o objeto é um dos grandes problemas da ciência e da filosofia.

Ainda segundo o mesmo autor, o objeto é representado na mente humana por idéias. Por estas idéias é possível distinguir elementos que aproximam este objeto de outros, formando ou possibilitando o seu enquadramento como gênero; esse mesmo processo indica elementos e características que, dentro desse gênero, torna o objeto diferente de outros objetos, com os quais tem semelhanças. Se o estudo se dirige, por exemplo, na tentativa de enquadrar o direito como fato social, procura-se na realidade social quais aqueles fenômenos que mais elementos têm de identificadores

Data recebimento: $17 / 05 / 88$ - Data aprovaçäo: 02/08/88

a Trabalho apresentado ao Curso de Mestrado em Direito das Relações Sociais como exigência final para conclusão da disciplina Teoria Geral do Direito, sob orientação do Prof. Luiz Fernando Coelho. 
com o direito. Chegando-se a uma identidade suficientemente forte e comprovada cientificamente, pode-se afirmar que o mesmo é um fenômeno sociológico. Dentro do campo da Sociologia, onde o objeto passa a ser inserido, ampliase a área de busca de elementos que torne esse objeto diferente dos demais ramos da sociologia. A este processo de distinguir e aproximar elementos do objeto, dá-se o nome de abstração.

Pelo resultado desse processo chega-se aos conceitos, que são formulados a respeito do objeto. $\mathrm{O}$ conhecimento, como meio de contato entre o sujeito e o objeto, é alcançado pela formulação dos conceitos, que sintetizam o processo de descoberta dos elementos identificadores e diferenciadores do objeto.

O conhecimento, nessa ordem de idéias, se dá na presença desses três elementos: o sujeito, o objeto e o conceito. Segundo Luiz Fernando Coelho (3:37), o conceito que constitui "as representaçōes pelas quais ocorre o conhecimento" realiza a sintese entre o sujeito e o objeto.

Essas noções sumárias sobre a forma de se conhecer o objeto de uma ciência têm, evidentemente, caráter genérico, o que as tornam aplicáveis a qualquer processo de conhecimento científico. Como no presente caso se trata de descortinar o conhecimento jurídico, diz-se que os ingredientes desse conhecimento são: o sujeito representado pelo jurista; o fenômeno jurídico como o objeto e os conceitos que são as formas mentais de relacionamento do sujeito com o seu objeto de estudo, no caso o direito. O centro desse processo de conhecimento, fruto das abstrações efetivadas pelo sujeito, são os conceitos.

Como o conhecimento está assentado numa relação entre o sujeito e o objeto, através dos mecanismos de abstração, é possível abordá-lo de três formas diferentes: a) a partir de conhecimento em si, analisando os seus elementos diferenciadores e também identificadores com determinado modelo de ciência; b) do ponto de vista do sujeito; e c) do ponto de vista do objeto, ou seja, da visão ontica sobre o mesmo.

Luiz Fernando Coelho, ressalvando ser o conhecimento uno, propõe denominar cada um desses planos ou dimensões de: plano epistemológico, plano lógico e plano jurídico em sentido estrito. (3:39).

No plano da epistemologia é o próprio conhecimento é que se transforma ou é eleito o objeto da ciência e o que se busca é saber que ciência é o direito e quais outras áreas do saber se ocupam ou podem se ocupar desse mesmo objeto. Neste plano não é o direito que está sendo enfocado como objeto e sim o conhecimento jurídico, aquele elemento que faz a ligação entre o sujeito e o objeto. No plano lógico discute-se a validade do próprio conhecimento jurídico. $\mathrm{O} \mathrm{ob}$ jetivo aqui é extrair noções de validade, de verdade e coerência do conhecimento com outros valores veritativos. A reflexão que se faz a respeito de tais aspectos do conhecimento se dá no plano lógico, resultando numa lógica do direito. Como o terceiro plano trata dos aspectos ônticos do objeto, busca-se descobrir o ser jurídico, ou seja, identificar ontologicamente o objeto da ciência jurídica, possibilitando chegar-se a um modelo de ciência a ser adotado. "Parece-me evidente que a elaboração de uma teoria do direito exige o prévio posicionamento quanto ao problema ontológico: o ser do direito é que vai determinar o estabelecimento de estratos de significação científica de um conhecimento voltado à realidade histórica-social definida como direito". (3:41).

\section{O MUNDO DO DIREITO}

Para J. Flóscolo da Nóbrega (12:1/7) o mundo em que fenômeno direito ocorre se apresenta ao homem em três planos distintos: como, natureza, como valor e como cultura. Descobrir em que plano do mundo está inserido o direito é assim tarefa do sujeito do conhecimento, ou seja, do jurista, aquele que se dedica à tarefa de se preparar intelectualmente para entender o fenômeno e tratá-lo científica e tecnicamente. No plano da natureza se encontra tudo aquilo que não depende da ação do homem para existir. Rege-se pelo princípio da causalidade. São as leis naturais que sempre ocorrem da mesma maneira, observadas certas circunstâncias. Se determinado objeto é lançado em um ambiente gravitacional, sabe-se, com certeza, que a sua tendência será cair ao solo. Assim, em todas as vezes em que se verificar a existência da gravidade o resultado será o mesmo. No mundo dos valores já se encontra a participação do homem, através de um processo de emprestar significados às coisas. Constata-se a existência de alguma coisa, e a ela é atribuída uma boa ou má qualidade. Já o mundo da cultura é aquele em que estão sintetizadas as realizaçôes do homem, através da adaptação que o mesmo faz da natureza para atender às suas necessidades primárias.

Pelas consideraçôes suscintamente feitas sobre cada um dos planos em que o mundo se apresenta, pode-se verificar que o direito não está no mundo da natureza, (6:120/121) em razão de que não se sujeita a normas fixas, que não variam no tempo; as leis naturais não podem ser violadas enquanto aquelas do direito são passíveis de violação. $O$ direi. to não é permanente no tempo e além disso varia de povo para povo.

Não é o direito exclusivamente valor, pois que tem vida objetiva, concreta, enquanto os valores são criaçōes subjetivas, são projeções do espírito sobre a natureza. Nas palavras de J. Flóscolo da Nóbrega, "o direito realiza valores, vive de valores, mas é, ao mesmo tempo, penetrado de elementos naturais, que o fazem participar, igualmente, do mundo da natureza". (12:6).

Conclui o mesmo autor que diante dessas considerações o direito não encontra sede exclusivamente em nenhum desses planos, pois participar a um só tempo de um e de outro: "da natureza, porque tem base na vida humana, nas relações sociais, e dos valores, pela significação que imprime a essas relações, orientando-as para a satisfação dos interesses comuns. $\hat{E}$, portanto, natureza valorada, moldada pelo valor e valor objetivado através de dados naturais. $O$ que significa que o direito é fato cultural e se situa no mundo da cultura". (12:6).

\section{O DIREITO SOB TRES ENFOQUES TRADICIONAIS}

A partir dessas observaçóes conclui o mesmo autor que o diretto e um dado social, pois produto da vida social. $\mathrm{U}$ direito não é resultado da exclusiva vontade do homem, mas fruto da atividade social, da vida em sociedade.

O direito é assim, produto condicionado mas que também condiciona o comportamento social, e o seu estudo passa pelo conhecimento dos fatores sociais que dão substrato à sua existência. Uma ciência nova cuida do estudo do direito como dado social: a sociologia jurídica. 
Este, entretanto, não é o único enfoque pelo qual o direto pode ser visto. Aliás, este é, em verdade, apenas um dos três enfoques que o fenômeno jurıdico é tradicionalmente encarado, como ensina Miranda Rosa: "Ele pode ser visto mediante a captação da realidade jurídica por meio de sua relação com as causas primeiras e os princípios fundamentais, no estudo da própria natureza do Direito e da sua significação essencial; temos, então, a Filosofia do Direito. Também pode ser encarado em termos adequados à atividade profissional dos juristas como um conjunto sistemático de normas de conduta, guardando lógica interna e de natureza dogmática; encontramos, sob esse aspecto, a ciência dogmático-normativa do Direito. E, finalmente, pode ser olhado como fato social, realidade do que ocorre na sociedade, causa e consequiência de outros fatos sociais, captando a realidade jurídica e projetando-a somente em relação a causas e princípios verificáveis; aqui estamos na área da sociologia juridica." (16:30).

À vista de que o tema trata do direito como fato social, ou seja, como fenômeno verificável no meio social, o ponto de partida para seu estudo é a sociologia jurídica.

Independentemente disso, comporta o trabalho, apreciação, ainda que em forma apenas de breve notícia, das outras vertentes do saber jurídico, como a filosofia do direito, voltada mais para os aspectos universais do direito, estudando suas origens e o colocando frente com a idéia de valor. A filosofia do direito busca a razão de ser do direito em face do homem. O' direito está ligado à idéia de sociedade (ubi socie. tas ibi jus), não sendo possível existir sociedade sem direito (9:4/5). A filosofia do direito, segundo Paulo Dourado de Gusmão, não é a ciência por que "não se forma do conhecimento, mas de interpretação, ou melhor de reflexões". (6:11)

Para Miguel Reale, (14:10) a missão da Filosofia do Direito é "portanto, de crítica da experiência jurídica, no sentido de determinar as suas condições transcendentais, ou seja, aquelas condições que servem de fundamento à experiência, tornando-a possivel".

Segundo o mesmo Reale, quando o advogado invoca a lei ao caso concreto, e o juiz, no seu trabalho forense, aplica os textos legais, dão por cumprida a função de cada um já que a norma legal é o ponto de partida de ambos. Para o filósofo aí começam os problemas, pois exsurgem os "por quês". Por que o juiz aplicou esta norma? Agiu corretamente? Fez justiça? Estas são preocupações próprias dos filósofos do direito. Não são as dos normativistas, que vêm o direito a partir, exclusivamente da norma. Para os dogmáticos o direito é a própria norma, que traz em si a idéia de prin. ćpio que deve ser aceito e observado pela sociedade. A corrente que adota a norma como centro do estudo do direito, parte do pressuposto de que só é jurídico aquilo que está normatizado. $\widehat{E}$ o resultado da aplicação da filosofia positivista sobre o qual assenta o modelo de organização social criado pela revolução burguesa, que substituiu o príncipe pelo princípio. O Estado, este ente ideal de organização social, detêm o monopólio da elaboração do direito. Não será direito aquele que não for resultado da vontade do Estado: o direito é único e estatal. Mesmo quando se fala em costume, é o mesmo tratado e aceito porque a própria norma permite. Seria o caso, no Brasil, do artigo $5 \%$ da Lei de Introdução ao Código Civil que expressamente autoriza a adoção do costume quando determinada situação não for expressamente regulada pela lei. A forma concreta de manifestação desse direito estatal e único é a norma.

Este modelo de concepção do direito não admite, na formação da ciência jurídica, a influência de outra área do conhecimento. O que ocorre antes da formulação da norma é questão de política legislativa, e depois, quando da sua aplicação, será de política judiciária, não de direito. Este deve ser abordado, cientificamente, a partir de sua vigência e eficácia, sem juizo valorativos.

No momento em que a norma entra em vigor, passa a integrar o que se convencionou chamar de "ordenamento jurídico" e como tal deve ser observada, não importando a visão do justo. O estudo dos critérios valorativos do direito encontraria sede na filosofia do Direito, por exemplo, mas não na ciência do direito. Expressão máxima e contemporânea dessa vertente é Hans Kelsen.

Kelsen formulou a sua "Teoria Pura do Direito" dirigi.. da ao estudo do direito positivo, donde procurou expurgar tudo o que não considerasse jurídico.

Esta preocupação na busca da pureza do direito é colocada logó no início de sua obra clássica: "Quando a si própria se designa como "pura" teoria do Direito, isto significa que ela se propõe garantir um conhecimento apenas dirigido ao Direito e exclui deste conhecimento tudo quanto não pertença ao seu objeto, tudo quanto se possa, rigorosamente, determinar como Direito. Quer isto dizer que ela pretende libertar a ciência jurídica de todos os elementos que the são estranhos. Esse é o princípio metodológico fundamental"s. $(8: 1)$

Kelsen representa um momento fundamental para $u$ estudo do direito e a despeito das criticas que se lhe possam fazer, representa um marco para a cultura universal do direito.

A pureza metodológica, proposta por Kelsen leva a que se considere o direito, visto a partir da norma, que decorre de uma norma fundamental, como justo, pois direito, produto da vontade estatal. A norma será então sempre justa e o aplicador ao utilizá-la no caso concreto estará fazendo justiça. Por este prisma, isento de valores e ideologia - aspecto sempre repudiado por Kelsen - toda sentença será justa, pois prolatada a partir da aplicação do direito. Esta forma de ver o direito causou a Kelsen o dissabor de reconhecer legítimo o diteito nazista que o perseguiu por sua ascendência judia.

A forma dogmático-normativista do direito cria "a impressão de que o núcleo do Direito é constituído em grande parte de princípios permanentes, incidindo as transformações principalmente sobre aspectos periféricos ou secundários da ordem jurídica, ou, então, operando as mudanças mais importantes segundo modos preestabelecidos e gradualmente, sem afetar a unidade interna do sistema".(16:12)

A escola dogmática domina a doutrina ocidental, nos países de economia capitalista, e obedece a um padrão de ideologia definido.

Os planos em que o direito pode ser estudado não estão limitados aos três já indicados, registrando-se obras de autores que buscaram outros enfoques, como o caso de Radbruch, para quem o direito pode ser visto segundo as seguintes maneira:

"A primeira é a própria da atitude que refere as realidades jurídicas aos valores (wertbeziehend), considerando o direito como facto cultural; é esta a atitude essencial da Ciência do Direito. A segunda é a atitude valorativa 
(bewertend) que considera o direito como um valor da cultura; é esta a atitude essencial da Filosofia do Direito. E finalmente é a terceira a atitude superadora dos valores (wertuberwindend) que considera o direito na sua essência, ou como não, dotado de essência; e é esta a atitude ou o tema da Filosofia-religiosa do direito." $(13: 46)$.

Radbruch foi neokantiano e entendia o direito-positivo - como um fenômeno cultural, exprimindo-se como uma aspiração para aquilo que é justo.

Os modelos de conhecimento do direito partem, cada uma delas, da separação dos elementos fato, valor e norma.

Mesmo reconhecendo a importância de cada um destes elementos na formação do direito como objeto de ciência, as três vertentes referidas elegem um deles, ao qual passa a atribuir maior jurisdicidade, construindo uma metodologia própria.

Assim é que para a Filosofia do Direito importa fundamentalmente, o elemento valor; para a sociologia, o fato social e histórico; e para a Ciência do Direito, a norma ordenadora de conduta. (14:509).

Miguel Reale diferentemente dessas correntes, desenvolve desde a década de 40, o que chamou de "Teoria Tridimensional do Direito", através da qual o direito é estudado a partir da integração dos três elementos supra referidos. A experiência jurídica, sob qualquer enfoque, não pode perder de vista a existência integrada desses três elementos.

O direito, para Reale, é fato, valor e norma ao mesmo tempo, tal como se expressa o dogma da santíssima trindade. Num momento ele é fato, no outro é valor e no terceiro é norma, sem, no entanto, deixar de ser todos os três ao mesmo tempo.

Afirma Reale que:... "a Teoria Tridimensional do Direito e do Estado, tal como a venho desenvolvendo desde 1940 , muito embora não empregasse então aquele termo, distingue-se das demais de caráter genérico ou especifico, por ser concreta e dinâmica, isto é, por afirmar que:

a) Fato, valor e norma estão sempre presentes e correlacionados em qualquer expressão da vida jurídica, seja ela es. tudada pelo filósofo ou o sociólogo do direito, ou pelo jurista como tal, enquanto que, na tridimensionalidade genérica ou abstrata, caberia ao filósofo apenas o estudo do valor, ao sociólogo o do fato e ao jurista o da norma (tridimensionalidade como requisito essencial ao direito)

b) A correlação entre aqueles três elementos é de natureza funcional e dialética, dada a 'implicação - polaridade' existente entre fato e valor de cuja tensão resulta o momento normativo, como solução superadora e integrante nos limites circunsciais de lugar e de tempo (concreção histórica do processo jurídico, numa dialética de implicação e complementariedade". (15:57).

\section{O DIREITO COMO FATO SOCIAL}

Limitamo-nos apenas à notícia de algumas das formas de como o direito é encarado, de vez que o objetivo dessas anotações é a sua abordagem como fato social, como produto da interação social.

Como dissemos, como fato social o Direito é objeto de estudo da sociologia jurídica, um dos ramos da sociologia genericamente considerada.
Na condição de ramo autônomo do conhecimento, a sociologia jurídica existe a bem pouco tempo, estando ainda engatinhando frente à filosofia do direito e ao dogmatismonormativista, por exemplo.

A formação da sociologia jurídica como ramo autônomo da ciência ocorreu com a escola de pensadores liderada por Durkheim, a partir, especialmente, de sua obra "A Divisão do Trabalho Social", onde, conforme A.L. Machado Neto $(10: 105 / 106)$ se aperfeiçoam os estudos das influências da sociedade sobre a formação do direito. Nesta obra Durkheim estuda dois tipos de solidariedade social: a mecânica e a orgânica. A medida em que a sociedade orgânica vai se sobrepondo à mecânica, o direito vai perdendo seu caráter repressivo e retributivo para assumir o caráter restituivo, que é a característica do direito civil e comercial de hoje.

Reconhecendo a Sociologia Jurídica como ramo autônomo do saber jurídico, os autores tratam de formular uma metodologia própria, além de buscar definir suas tarefas.

A propósito do segundo ponto, ou seja, das tarefas da sociologia jurídica, Paulo Dourado de Gusmão elenca algumas que considera fundamentais:

" 1 a , demonstrar que cada direito é uma função de um tipo de vida social e das condições econômicas, morais, geográficas e demográficas da sociedade; 2 a, indicar os fatores sociais das transformações juridicas; 3 a , elaborar uma teoria sociológica do conhecimento jurídico, do saber juridico, mostrando os objetivos provocadores das idéias juridicas; 4 a, verificar os resultados sociais das regras, teorias e instituições jurídicas, a fim de facilitar o trabalho do legislador, do juiz e do jurista na reforma e interpretação do direito; 5 ; estabelecer a função e o fundamento sociais, não do direito, mas dos direitos; 6a, apurar os fatores sociais de fatos jurídicos (divórcio, casamento, crimes, etc.) e a inter-relação entre esses fatos e a realidade social; 7 a, estabelecer os tempos e espaços sócio-culturais do direito; 8a, verificar os fatos sociais que determinam a presença em diferentes direitos de elementos jurídicos comuns e de elementos jurídicos diversos; 9a definir o direito em termos sociológicos." $(7: 36 / 37)$

À vista de que, para a sociologia jurídica, o direito é fato social, impõe-se, à luz da sociologia geral, saber o que seja, exatamente "fato social".

Para tanto socorremo-nos dos ensinamentos de Durkheim. (5:1/11) quando diz que o homem quando cumpre obrigações contraídas, quando atende aos deveres de irmão, de esposo, por exemplo, realiza atos que estão fora dele próprio. Tais manifestações são externas, e vêm de fora para dentro do indivíduo. Mesmo quando está de acordo, esta realidade objetiva, carregada de coercibilidade, é sentida pelo indivíduo. Cada um dos membros da sociedade submete-se a essas imposições, aceitando-as como válidas socialmente. Nestas condiçōes, diz o pensador francês, o indivíduo é colocado frente a uma ordem de fatos de características peculiares: "consistem em maneiras de agir, de pensar e de sentir exteriores ao indivíduo, dotadas de um poder de coerção em virtude do qual se the impõem. Por conseguinte, não poderiam se confundir com os fenômenos orgânicos, já que consistem em representações e em ações; nem com os fenômenos psíquicos que não têm existência senão na consciência individual e por meio dela. Constituem, pois, uma espécie nova e é a eles que deve ser dada e reservada a qualifi- 
cação de sociais". (1:74/75).

A partir dessas colocações, Durkheim apresenta a seguinte definição de fato social: " $E$ fato social toda maneira de agir, fixa ou não, suscetivel de exercer sobre o individuo uma coerção exterior, ou mais ainda, que é geral na extensão de uma sociedade dada, apresentando uma existência própria, independente das manifestações individuais que possa ter." (1:74/75).

Extrai-se da lição de Durkheim que o direito é fenômeno que se observa no meio social, como manifestação das realidades da sociedade. Não nasce da vontade individual, mas como manifestação de uma necessidade social. Sua origem decorre da existência da sociedade organizada, a qual serve-se do direito como instrumento eficaz de controle social.

$O$ direito estabelece normas de conduta, às quais corres. ponde uma coerção. Estas normas são elaboradas pelas instituiçóes que a sociedade cria e mantém com o fim de formular o direito, o qual refletirá a realidade axiológica daquele momento. A norma, a partir dessa visão, reflete uma realidade social, pois responde a uma necessidade que os in. divíduos coletivamente apresentaram.

O direito, neste plano, es estudado a partir da realidade que o condiciona, focalizando os fatores de sua transformação, desenvolvimento e declínio. A norma é apenas o resultado da realidade em que o direito está inserido, e desta forma é vista. O direito aqui não é a norma, mas sim o fato social, o fenômeno verificável a partir de condicionantes sociais.

Esta forma de ver o direito implica em negar o caráter de permanència que o mesmo tem no âmbito do dogmatismo-normativista. Ele será um fenômeno mutável de acordo com as mudanças operadas no meio em que ele aparece, se desenvolve e desaparece. E mutável no tempo e no espaço. No tempo porque a cada época corresponde uma realidade jurídica. E no espaço porque é fenômeno variável de sociedade para sociedade. Cada realidade social condiciona por ordens jurídicas criadas à sua semelhança. Isto impediria, por exemplo, que um sistema jurídico fosse transplantado de um para outro país, sem observância de suas realidades sociais. Noçōes de cunho mais universais, pertinentes a valores considerados universalmente poderiam ser adotados em países diferentes, mas sempre tendo em conta as peculiaridades de cada um. A forma de proteger a liberdade, por exemplo, que é um bem universal, toma formas diferentes, segundo a realidade de cada sociedade.

Outro aspecto importante é o fato de que, por ser a realidade social condicionante da normatividade juridica, o costume passa a ser elemento importante na formacão do direito. $\mathrm{O}$ costume que surge espontaneamente no meio social força a edição de normas regrando situações não percebidas desde logo pelo legislador, as quais passam a integrar o ordenamento jurídico. Às vezes as regras de costume são aceitas pelo ordenamento que as tornam válidas e observáveis, mesmo na condição de costume. Isto se observa mais facilmente no campo das relações comerciais. São conhecidos os exemplos de contratos verbais firmados por negociantes de gado bovino na região de Barretos, no Estado de São Paulo, em cifras infinitamente superiores àquelas referidas no artigo 401 do CPC e que mesmo assim, são passiveis de prova testemunhal. O costume, como realidade social palpável supera o direito escrito e é aceito como válido.

Como fato social, o direito está no mundo do real, ou seja, no mundo do ser, enquanto que do ponto de vista da ciência juridica, o direi to é norma, ou seja, dever ser.

Ontologicamente, o direito, sob o prisma da sociologia jurídica, é um fenồneno complexo e não apenas a norma abstrata que expressa, através de um modelo lingüístico, uma forma de conduta.

Uma das conseqüências disso é que sob o ponto de vista do dogmatismo, o ato de julgar não cria direito, pois o mesmo é antecedente, pré-existe, enquanto que, se o mesmo é considerado como resultante de uma realidade social, o ato de aplicar a norma resulta na criação de um direito que é formado no instante em que o julgador soluciona a lide.

\section{CONCLUSÃO}

A sociologia jurídica, tal como a dogmática, pressupõe a existência do direito, diferenciando-se entre si pelo enfoque que dão ao fenômeno jurídico. A sociologia jurídica aborda o direito como fruto da atividade social, a dogmática parte da norma abstratamente considerada.

Em comum, o fato de tomarem o direito como instrumento de controle social; asism o direito não é instrumento de mudança e sim de manutenção e quando muito, de re. forma da ordem social.

Em primeiro lugar julgamos oportuno questionar sobre a existencia de uma ordem social e a quem interessa a idéia de ordem social.

A vitoriosa sociedade burguesa elegeu como modelo ideal de organização social o Estado Moderno; a sustentação filosófica foi buscá-la no positivismo e o sistema econômico, o capitalismo, escudando na propriedade privada e na livre iniciativa. Ao longo do tempo o ideal preconizado por este modelo de sociedade tem redundado num evidente embuste, pois é reconhecidamente associado à idéia de privilégios classistas, onde a "livre iniciativa" sempre pertenceu, ao que detém o capital. A iniciativa é efetivamente livre para os que detém o monopólio dos bens de produção.

Dentro deste quadro histórico encontramos o direito como fiel escudeiro dos interessados em manter a ordem social. Ocorre que ordem pressupõe a conveniente disposição de elementos para a obtenção de fins específicos. Se falamos de uma ordem social, falamos de um modelo ideal de convivência que tem um objetivo: o bem comum. Mas será que é asism que ocorre? Será que todos os membros das sociedades visam o bem comum? O que é o bem comum?

A nosso ver, o direito traz engastado em carga indiscutivel de ideologia, representada pelos mitos sociais, como aquele do bem comum a que nos referimos anteriormente.

Daí não ser satisfatório o estudo da ciência do direito, pois pretensamente pura, quando se sabe que não é esta a realidade em que o homem vive. $O$ direito não pode ser um modelo abstrato de conduta, independente da realidade em que vai produzir efeitos. Não é difícil reconhecer-se toda a genialidade de Kelsen; o que não é possível é admitir-se que, buscando formular uma teoria de direito a partir da norma, abstrair o fenômeno direito das influências exercidas pelos fatos sócioculturais.

$\mathrm{O}$ que também não satisfaz na sociologia jurídica é que a metodologia adotada parte da verificação pura e simples do fenômeno, sem que norteie uma preocupação de utilizá-lo como instrumento de mudança da ordem social. As diferenças com a dogmática se dão apenas no plano teórico, pois que a sociologia não propõe uma visão renovadora đa socie- 
dade a partir đa criação do direito.

Em ambos os enfoques, o dogmático e o sociológico releva-se a carga ideológica do direito, admitindo-se que o mesmo mantenha a sua característica de instrumento de manutenção do "status" tal como ele se apresenta.

As faculdades de direito ocidentais, de seu termo, coerentes com o modelo ideal de sociedade criado pela burguesia, não se interessam pela visão crítica que todo método de conhecimento deve ter. (11:23) Daí a formação de profissionais com uma preocupação exclusivamente prática, sem nenhum espirito crítico sobre o instrumental que lhe é colocado à mão.

O direito não pode ser visto apenas como algo conservador. Deve ser encarado como instrumento de mudanças da ordem social, sempre que esta se mostrar contrária aos in teresses da maioria. O direito é feito para viger entre pessoas humanas e não seres ideais. Não pode servir de controle e manutenção dos interesses de classes e nem como instrumento de repressão de liberdades, como ocorre nas sociedades socialistas.

\begin{abstract}
In this word the intent is to demonstrate that law is always a verifiable phenomenon with social reality, thus a social fact. Law, as a scientific object, can be studied in three dimensions: through phylosophy of law, through the "dogmatic-normative" science of law and through sociological justice. Miguel Reale, creator of the "three dimensional theory of law", afirms that law is, as the same time, fact, value and norm. Following this theory, various considerations can be developed, parallel with the "critical theory", defended by Luiz Fernando Coelho, who sees law as an instrument for radical social change and not simply a regulator of established social order. The development of this theme was exaustively investigated during the classes of phylosophy of law, part of the program for the Masters Degree in Law of Social Relations at the Universidade Estadual de Londrina and this paper is synthesis of our development.
\end{abstract}

KEY WORDS: Social fact; Phylosophy of law; Dogmatic justice; Sociological justice; Three dimensional theory; Critical theory.

\title{
REFERENCIAS BIBLIOGRÄFICAS
}

1. CASTRo, Anna Maria de \& DIAS, Edmundo F. Introdução do pensamento sociológico. s.e.p., Eldorado, 1985. $341 \mathrm{p}$.

2. COELHO, Luiz Fernando. Introdução à crítica do direito. Curitiba, HDV, 1983. 212 p.

3. Lógica juridica e interpretação das leis. Rio de Janeiro, Forense, 1981. 359 p.

4. Teoria e critica do direito.

Curitiba, HDV, 1983. 416 p.

5. DURKHEIM, Emile. As regras do método sociologico. São Paulo, Ed. Nacional, 1982. 128 p.

6. GUSMÃo, Paulo Dourado de. Filosofía do direito. Rio de Janeiro, Forense, 1985. $191 \mathrm{p}$.

7. Introdução ao estudo do direito. Rio de Janeiro, Forense, 1986. $556 \mathrm{p}$.

8. KELSEN, Hans. Teoria pura do direito. Coimbra, Sucessor, 1962. R.V.
9. LITRENTO, Oliveiros. Curso de filosofio do direito. Rio de Janeiro, Forense, 1984、321 p.

10. MACHADO NETO, A.L. Sociologia jurídica. São Paulo, Saraiva, $1984.420 \mathrm{p}$

11. MAILLE, Michel. Uma introdução à crítica ao direito. s.e.p., Braga, s.d. 318 p.

12. NÓBREGA, J. Flósculo da Introdução do direito. s.e.p., Sugestões Literárias, $1987.232 \mathrm{p}$.

13. RADBRUCH, Gustav Filosofia do direito. Coimbra, Sucessor, 1979. $430 \mathrm{p}$.

14. REALE, Miguel Filosofia do direito. São Paulo, Saraiva, 1987. $749 \mathrm{p}$.

15. Teoria Tridimensional do Direito. São Paulo, Saraiva, 1979. 93 p.

16. ROSA, F.A. Miranda. Sociologia do direito. Rio de Janeiro, Zahar, 1978. $230 \mathrm{p}$. 